\title{
Developing of Measurement of Independence Characteristic in Middle School Students Mathematics and Science
}

\author{
Pengembangan Instrumen Pengukuran Karakter \\ Kemandirian pada Siswa SMA Matematika dan IPA
}

\author{
Supardi U.S. (*) \\ Fakultas Matematika dan Ilmu Pengetahuan Alam \\ Universitas Indraprasta PGRI
}

$\begin{array}{ll}\text { Received: } & \text { July 13, } 2018 \\ \text { Revised: } & \text { July 19, } 2018 \\ \text { Accepted: } & \text { July 20, } 2018\end{array}$

\begin{abstract}
The purpose of this study to design a measurement instrument independence character of middle school students. Research using research and development $(\mathrm{R} \& \mathrm{D})$. Stages of the research process include: reviewing the concept, making the construct and design the instruments, experts' assessment, the empirical pre-test, and empirical testing. Test experts were conducted by experts through quantitative and qualitative assessments were followed by improvements to the instrument. Pre empirical testing was done by trial and instruments in small scale followed by repair and selection of items. Empirical testing is a field test on a large scale at middle school students who were followed by the selection of grains and calculation of reliability of the instrument. Research and development results obtained as follows. (1) Measurement code developed with the student independence four dimensions: freedom, initiative, progressive and resilient, and confident. Dimension of freedom comprising: able to make their own choices and able to perform his own activities. Dimension Initiative consists of: being able to think and act in an indigenous, and doing creative activities. The results of this study are expected secondary school teachers can have a reference or guidelines for measuring the character of student independence.
\end{abstract}

Keywords: Development Instrument, Independence, Middle School Students, Instruments Validation

(*) Corresponding Author: $\quad$ supardius77@gmail.com

How to Cite: Supardi. (2018). Developing of measurement of independence characteristic in middle school student mathematics and science. Formatif: Jurnal Ilmiah Pendidikan MIPA, 8 (2): 111-118. http://dx.doi.org/10.30998/formatif.v8i2.2650

\section{PENDAHULUAN}

Pendidikan nilai-nilai karakter bangsa merupakan kebutuhan yang harus tetap terjaga agar setiap generasi dapat memahami dengan baik dan mampu mengangkat citra bangsa Indonesia di mata bangsa lain. Apabila setiap warga negara memiliki karakter bangsa yang baik dan melaksanakan dengan baik pula, maka kehidupan bermasyarakat dan bernegara yang terjadi akan baik pula. Selain itu, karakter merupakan salah satu unsur dari jati diri selain kepribadian.

Semakin pesatnya perkembangan teknologi informasi menyebabkan semakin mudah pula seseorang dalam mengakses berbagai informasi dari dalam maupun luar negeri. Hal ini, mengakibatkan informasi yang diperoleh dari kemajuan teknologi, secara 
langsung atau tidak langsung memengaruhi nilai-nilai kesadaran berbangsa dan bernegara seseorang. Dampaknya, pola hidup dan kehidupan seseorang dipengaruhi oleh budaya dari luar yang diperoleh melalui pemanfaatan teknologi informasi tersebut. Begitu pentingnya nilai-nilai kebangsaan bagi kelangsungan hidup suatu bangsa maka setiap bangsa berusaha menanamkan rasa nasionalisme dan kebangsaan ini melalui pendidikan formal, informal, dan non formal. Bahkan pemerintah berupaya dengan menetapkan agar mata pelajaran yang berhubungan dengan penanaman nilai-nilai karakter bangsa diajarkan pada siswa dari tingkat Sekolah Dasar (SD) sampai dengan Perguruan Tinggi (PT).

Hal tersebut mengacu pada pernyataan dalam UU nomor 20 tahun 2003 tentang Sistem Pendidikan Nasional pasal 3 bahwa, "Pendidikan nasional berfungsi mengembangkan kemampuan dan membentuk karakter watak serta peradaban bangsa yang bermartabat dalam rangka mencerdaskan kehidupan bangsa, bertujuan untuk berkembangnya potensi peserta didik agar menjadi manusia yang beriman dan bertaqwa kepada Tuhan Yang Maha Esa, berakhlak mulia, sehat, berilmu, cakap, kreatif, mandiri, dan menjadi warga negara yang demokratis dan bertanggung jawab." Dari hal tersebut, artinya melalui pendidikan diharapkan setiap warga Negara khususnya peserta didik memiliki nilai-nilai karakter yang baik seperti, kreatif dan mandiri. Dengan memiliki nilai-nilai karakter yang baik, maka jati diri peserta didik akan baik pula.

Dalam kurikulum 2013 juga ditekankan bahwa pendidikan karakter kebangsaan merupakan materi yang terintegrasi dalam mata pelajaran yang disampaikan kepada peserta didik. Tujuan dari hal tersebut agar peserta didik memahami karakter bangsa Indonesia dan menyadari bahwa bangsa Indonesia memiliki ciri-ciri yang berbeda dengan bangsa lain sehingga tidak mudah menerima paham atau ajaran dari luar yang tidak sesuai dengan nilai-nilai karakter bangsa Indonesia.

Salah satu karakter bangsa yang perlu dijaga dan ditumbuhkembangkan adalah karakter kemandirian. Kemandirian merupakan suatu sikap seseorang yang menunjukkan kemampuan dalam melakukan suatu aktivitas dengan upaya sendiri. Desmita (2009: 185) bahwa kemandirian atau otonomi adalah kemampuan untuk mengendalikan dan mengatur pikiran, perasaan, dan tindakan sendiri secara bebas serta berusaha untuk mengatasi perasaan-perasaan malu dan keraguan.

Salah satu upaya menumbuhkembangkan karakter kemandirian adalah melalui kegiatan ektrakurikuler pramuka. Dalam kegiatan ekstrakurikuler kepramukaan, peserta didik dilatih dan dikembangkan nilai-nilai karakter bangsa. Menurut Patimah (2011) secara umum nilai-nilai karakter yang tercantum dalam pembinaan kegiatan pramuka adalah percaya diri, patuh pada aturan-aturan sosial, menghargai keberagaman, berpikir logis, kritis, kreatif, dan inovatif, mandiri, pemberani, bekerja keras, tekun, ulet/gigih, disiplin, visioner, bersahaja, bersemangat, dinamis, pengabdian, tertib, dan konstruktif.

Karakter kemandirian dapat terlihat baik secara sikap maupun tindakan, sehingga seseorang mampu menilai karakter kemandirian orang lain. Desmita (Suhendri, 2013: 109) bahwa kemandirian biasanya ditandai dengan beberapa ciri, antara lain: kemampuan menentukan nasib sendiri, kreatif dan inisiatif, mengatur tingkah laku, bertanggung jawab, mampu menahan diri, membuat keputusan-keputusan sendiri, serta mampu memecahkan masalah tanpa ada pengaruh dari orang lain.

Namun untuk mengukur tingkat karakter kemandirian diperlukan suatu instrumen yang baku. Sehingga dalam penelitian ini akan dirancang dan dikembangkan suatu instrumen baku untuk mengukur kemandirian. Menurut Griffin (Harsiati, 2010: 53) "instrumen baku adalah instrumen yang memiliki karakteristik: (1) Disusun oleh para pakar, instrumen dikalibrasi, dianalisis, dan diperbaiki, (2) Mempunyai petunjuk pelaksanaan dan penyekoran yang jelas, dan (3) Memiliki acuan norma untuk menginterpretasikan suatu skor. Tes atau instrumen baku merujuk pada tes (instrumen) 
yang telah memiliki identitas hasil uji coba dan memiliki petunjuk administrasi serta level performansi.

\section{METODE}

Metode penelitian yang digunakan adalah metode penelitian dan pengembangan (research and development). "Metode penelitian dan pengembangan (research and development) adalah metode penelitian yang digunakan untuk menghasilkan produk tertentu, dan menguji keefektifan produk tersebut." (Sugiyono, 2007: 407). Teknik analasis data yang digunakan adalah analisis deskripitif evaluatif.

Ada beberapa tahapan dalam penelitian pengembangan khususnya pengembangan instrumen. Hal ini sesuai pendapat Djaali dan Muldjono (2008: 61) yang menyatakan bahwa langkah-langkah mengembangkan instrumen baku meliputi: 1) Merumuskan konstruk berdasarkan sintesis teori-teori yang dikaji, 2) Dari konstruk dikembangkan dimensi dan indikator variabel yang hendak diukur, 3) Membuat kisi instrumen dalam tabel spesifikasi yang memuat dimensi, indikator, nomor butir, dan jumlah butir, 4) Menetapkan besaran atau parameter dalam suatu rentangan kontinum, 5) menulis butirbutir instrumen, 6) Melakukan proses validasi, 7) Melakukan validasi teoritik, 8) Merevisi berdasarkan hasil panel, 9) Melakukan penggandaan untuk ujicoba, 10) Uji coba empiris di lapangan, 11) Pengujian validitas empiris, 12) Berdasarkan hasil analisis butir, butirbutir yang tidak valid dikeluarkan atau diperbaiki, butir yang valid dirakit kembali, 13) Menghitung reliabilitas, dan 14) Perakitan kembali butir-butir yang valid. Prosedur dalam penelitian ini seperti pada gambar 1 .

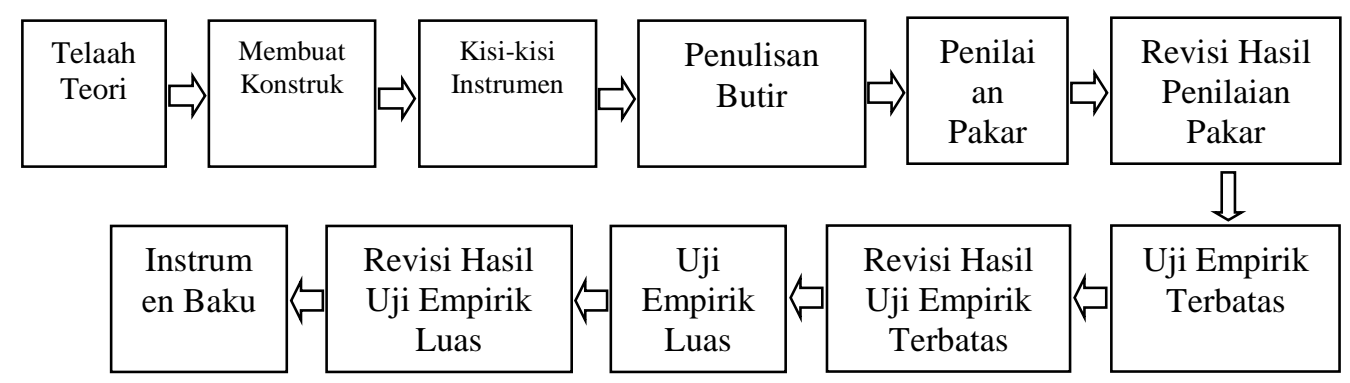

Gambar 1. Prosedur Pengembangan Instrumen Baku

Sumber data dalam penelitian ini terdiri dari, bahan kepustakaan, pakar, dan siswa SMA/SMK/MA. Teknik pengumpulan data yang digunakan dalam penelitian ini terdiri dari, studi kepustakaan, wawancara, dan kuisioner. Instrumen yang digunakan terdiri dari, jurnal, buku, bahan bacaan lain, lembar penilaian, dan kuisioner.

Desain produk yang dikembangkan yaitu berupa instrumen pengukuran yang terdiri dari kisi-kisi dan butir pernyataan serta petunjuk pengisian dan petunjuk penggunaan. Kemudian produk tersebut dilakukan penilaian melalui 3 tahap, yaitu (1) Penilaian konstruk oleh pakar yang terdiri dari, satu orang pakar bidang pembelajaran, satu orang pakar bidang pendidikan bahasa, dan satu orang pakar bidang evaluasi pembelajaran. Penilaian oleh pakar dalam bentuk kualitatif dan kuantitatif. Penilaian bentuk kualitatif berkaitan dengan penilaian terhadap ketatabahasaan, kesesuaian dimensi dengan konstruk, kesesuaian indikator dengan dimensi, dan kesesuaian butir dengan indikator. Penilaian bentuk kuantitatif dalam lembar penilaian yang terdiri dari 19 indikator penilaian yang terbagi menjadi 3 aspek, yaitu aspek konstruk, aspek keterbacaan, dan aspek kepraktisan. Skala penilaian 1 sampai 5 dengan taraf validitas 
konstruk yang dikembangkan berdasarkan nilai median (Md) dan Kuartil (Q). Nilai median tersebut selanjutnya ditafsirkan berdasarkan kriteria: $1-2$ berarti diganti, 3 berarti diperbaiki, 4-5 berarti baik atau dipertahankan. "Semakin tinggi nilai median berarti semakin baik atau relevan pernyataan dengan konstruk variabel yang hendak diukur. Selain itu, semakin kecil nilai Q3 - Q1 berarti semakin kuat pernyataan pakar." (Djaali dan Muldjono, 2008: 73).

\section{HASIL DAN PEMBAHASAN}

\section{Hasil}

Rancangan instrumen awal untuk mengukur karakter kemandirian dalam bentuk kisi-kisi seperti pada tabel 1.

Tabel 1. Kisi-Kisi Instrumen Kemandirian Awal

\begin{tabular}{|c|c|c|c|c|c|}
\hline \multirow[t]{2}{*}{ No } & \multirow[t]{2}{*}{ Dimensi } & \multirow[t]{2}{*}{ Indikator } & \multicolumn{2}{|c|}{ Butir Pernyataan } & \multirow{2}{*}{$\begin{array}{c}\text { Jumlah } \\
\text { Butir }\end{array}$} \\
\hline & & & Positif & Negatif & \\
\hline 1 & Kebebasan & $\begin{array}{l}\text { Memiliki kemampuan } \\
\text { menentukan pilihan }\end{array}$ & 1,2 & 3,4 & 4 \\
\hline \multirow[t]{2}{*}{2} & Inisiatif & $\begin{array}{l}\text { Mampu berpikir dan bertindak } \\
\text { secara orsinil }\end{array}$ & 5,6 & 7,8 & 4 \\
\hline & & Memiliki kreatifitas & 9,10 & 11,12 & 4 \\
\hline \multirow[t]{2}{*}{3} & Progresif dan & Memiliki ketekunan & 13,14 & 15,16 & 4 \\
\hline & & $\begin{array}{l}\text { Merencanakan dan mewujudkan } \\
\text { harapan-harapan }\end{array}$ & 17,18 & 19,20 & 4 \\
\hline 4 & Percaya diri & $\begin{array}{l}\text { Memiliki kepercayaan terhadap } \\
\text { kemampuan sendiri }\end{array}$ & 21,22 & 23,24 & 4 \\
\hline 5 & $\begin{array}{l}\text { Pengendalian } \\
\text { diri }\end{array}$ & $\begin{array}{l}\text { Mampu mengendalikan diri } \\
\text { dalam melakukan suatu aktivitas }\end{array}$ & 25,26 & 27,28 & 4 \\
\hline \multirow[t]{3}{*}{6} & $\begin{array}{l}\text { Bertanggung } \\
\text { jawab }\end{array}$ & $\begin{array}{l}\text { Menyesuaikan diri dengan } \\
\text { lingkungan }\end{array}$ & 29,30 & 31,32 & 4 \\
\hline & & $\begin{array}{l}\text { Berani mengambil resiko atas } \\
\text { pilihannya }\end{array}$ & 33,34 & 35,36 & 4 \\
\hline & & Jumlah Butir & 18 & 18 & 36 \\
\hline
\end{tabular}

Langkah berikutnya adalah penilaian rancangan instrumen yang dikembangkan oleh pakar. Penilaian pakar terkait dengan kesesuaian dimensi, indikator, butir dan kalimat pernyataan. Penilaian dari pakar merupakan tahap pertama dalam memvalidasi instrumen secara konstruk. Hasil penilaian pakar secara kualitatif berperan dalam perubahan kisi-kisi instrumen yang dikembangkan. Penilaian dari pakar memiliki peranan sebagai expert judgement, artinya penilaian dari pakar sangat berpengaruh terhadap instrumen yang dikembangkan. Walaupun demikian, kadang-kadang penilaian dari pakar bersifat subjektif sesuai dengan bidang keahlian pakarnya. Namun kadang-kadang penilaian pakar bersifat subjektif tergantung dari latar belakang atau bidang keahlian pakarnya. (Mardapi, 2011: 338). Hasil penilaian pakar pada rancangan instrumen awal dalam bentuk penilaian kualitatif dan kuantitatif. Kisi-kisi instrumen kemandirian hasil penilaian pakar seperti tabel 2 . 
Formatif: Jurnal Ilmiah Pendidikan MIPA

Vol. 8, No. 2, Agustus 2018, pp. 111-118

p-ISSN: 2088-351X

e-ISSN: 2502-5457

DOI: http://dx.doi.org/10.30998/formatif.v8i2.2650

Tabel 2. Revisi Kisi-Kisi Instrumen Kemandirian Hasil Penilaian Pakar

\begin{tabular}{|c|c|c|c|c|c|}
\hline \multirow[t]{2}{*}{ No } & \multirow[t]{2}{*}{ Dimensi } & \multirow[t]{2}{*}{ Indikator } & \multicolumn{2}{|c|}{ Butir Pernyataan } & \multirow{2}{*}{$\begin{array}{c}\text { Jumlah } \\
\text { Butir }\end{array}$} \\
\hline & & & Positif & Negatif & \\
\hline \multirow[t]{2}{*}{1} & Kebebasan & $\begin{array}{l}\text { Mampu menentukan pilihan } \\
\text { sendiri }\end{array}$ & 1,2 & 3,4 & 4 \\
\hline & & $\begin{array}{l}\text { Mampu melakukan aktivitas } \\
\text { sendiri }\end{array}$ & 5,6 & 7,8 & 4 \\
\hline \multirow[t]{2}{*}{2} & Inisiatif & $\begin{array}{l}\text { Mampu berpikir dan bertindak } \\
\text { secara orsinil }\end{array}$ & 9,10 & 11,12 & 4 \\
\hline & & $\begin{array}{l}\text { Melakukan aktivitas yang } \\
\text { kreatif }\end{array}$ & 13,14 & 15,16 & 4 \\
\hline \multirow[t]{2}{*}{3} & $\begin{array}{l}\text { Progresif dan } \\
\text { ulet }\end{array}$ & $\begin{array}{l}\text { Melakukan aktivitas secara } \\
\text { cermat dan teliti }\end{array}$ & $17,18,33$ & 19,20 & 5 \\
\hline & & $\begin{array}{l}\text { Merencanakan dan } \\
\text { mewujudkan harapan-harapan }\end{array}$ & $21,22,34$ & 23,24 & 5 \\
\hline \multirow[t]{3}{*}{4} & Percaya diri & $\begin{array}{l}\text { Percaya pada kemampuan } \\
\text { sendiri }\end{array}$ & $25,26,35$ & 27,28 & 5 \\
\hline & & $\begin{array}{l}\text { Berani mengambil resiko dan } \\
\text { menerima konsekuensinya }\end{array}$ & $29,30,36$ & 31,32 & 5 \\
\hline & & Jumlah Butir & 20 & 16 & 36 \\
\hline
\end{tabular}

Tahapan selanjutnya adalah instrumen yang dikembangkan kemudian diujikan secara terbatas kepada siswa. Selain diuji oleh para pakar, instrumen baku yang dikembangkan harus diujicobakan kepada responden di lapangan atau peserta didik yang telah ditentukan. Aiken yang dikutip Harsiati (2010: 54) menyatakan selanjutnya ditambahkan bahwa tes baku adalah yang dipersiapkan oleh pakar pengukuran, yang biasanya telah diujicobakan pada kelompok norma. Kisi-kisi instrumen hasil uji coba terbatas seperti pada tabel 3 .

Tabel 3. Revisi Kisi-Kisi Instrumen Kemandirian Hasil Uji Coba Terbatas

\begin{tabular}{|c|c|c|c|c|c|}
\hline \multirow[t]{2}{*}{$\mathrm{No}$} & \multirow{2}{*}{ Dimensi } & \multirow{2}{*}{ Indikator } & \multicolumn{2}{|c|}{ Butir Pernyataan } & \multirow{2}{*}{$\begin{array}{c}\text { Jumlah } \\
\text { Butir }\end{array}$} \\
\hline & & & Positif & Negatif & \\
\hline \multirow[t]{2}{*}{1} & Kebebasan & $\begin{array}{l}\text { Mampu menentukan pilihan } \\
\text { sendiri }\end{array}$ & 1,2 & 3,4 & 4 \\
\hline & & $\begin{array}{l}\text { Mampu melakukan aktivitas } \\
\text { sendiri }\end{array}$ & 5,6 & 7,8 & 4 \\
\hline \multirow[t]{2}{*}{2} & Inisiatif & $\begin{array}{l}\text { Mampu berpikir dan bertindak } \\
\text { secara orsinil }\end{array}$ & 9,10 & 11,12 & 4 \\
\hline & & $\begin{array}{l}\text { Melakukan aktivitas yang } \\
\text { kreatif }\end{array}$ & 13,14 & 15,16 & 4 \\
\hline \multirow[t]{2}{*}{3} & $\begin{array}{l}\text { Progresif dan } \\
\text { ulet }\end{array}$ & $\begin{array}{l}\text { Melakukan aktivitas secara } \\
\text { cermat dan teliti }\end{array}$ & 17,18 & 19,20 & 4 \\
\hline & & $\begin{array}{l}\text { Merencanakan dan } \\
\text { mewujudkan harapan-harapan }\end{array}$ & 21,22 & 23,24 & 4 \\
\hline \multirow[t]{3}{*}{4} & Percaya diri & $\begin{array}{l}\text { Percaya pada kemampuan } \\
\text { sendiri }\end{array}$ & 25,26 & 27,28 & 4 \\
\hline & & $\begin{array}{l}\text { Berani mengambil resiko dan } \\
\text { menerima konsekuensinya }\end{array}$ & 29,30 & 31,32 & 4 \\
\hline & & Jumlah Butir & 16 & 16 & 32 \\
\hline
\end{tabular}


Selain pengujian secara terbatas, instrumen yang dikembangkan diujikan secara luas, artinya jumlah responden yang dijadikan sampel untuk pengujian instrumen sebanyak 10 kali jumlah butir yang dikembangkan. Dalam uji coba instrumen, sampel yang digunakan harus memenuhi syarat. Menurut Kerlinger yang dikutip Harsiati (2010: 54) bahwa rekomendasi umum banyaknya sampel 10 kali lipat butir yang akan diujicobakan. Kisi-kisi instrumen hasil uji coba luas dan ditetapkan sebagai instrumen baku terlihat pada tabel 4.

Tabel 4. Kisi-Kisi Instrumen Kemandirian Baku

\begin{tabular}{|c|c|c|c|c|c|}
\hline \multirow[t]{2}{*}{ No } & \multirow[t]{2}{*}{ Dimensi } & \multirow[t]{2}{*}{ Indikator } & \multicolumn{2}{|c|}{ Butir Pernyataan } & \multirow{2}{*}{$\begin{array}{l}\text { Jumlah } \\
\text { Butir }\end{array}$} \\
\hline & & & Positif & Negatif & \\
\hline \multirow[t]{2}{*}{1} & Kebebasan & $\begin{array}{l}\text { Mampu menentukan pilihan } \\
\text { sendiri }\end{array}$ & 1,2 & 3,4 & 4 \\
\hline & & $\begin{array}{l}\text { Mampu melakukan aktivitas } \\
\text { sendiri }\end{array}$ & 5,6 & 7,8 & 4 \\
\hline \multirow[t]{2}{*}{2} & Inisiatif & $\begin{array}{l}\text { Mampu berpikir dan bertindak } \\
\text { secara orsinil }\end{array}$ & 9,10 & 11,12 & 4 \\
\hline & & $\begin{array}{l}\text { Melakukan aktivitas yang } \\
\text { kreatif }\end{array}$ & 13,14 & 15,16 & 4 \\
\hline \multirow[t]{2}{*}{3} & $\begin{array}{l}\text { Progresif dan } \\
\text { ulet }\end{array}$ & $\begin{array}{l}\text { Melakukan aktivitas secara } \\
\text { cermat dan teliti }\end{array}$ & 17,18 & 19,20 & 4 \\
\hline & & $\begin{array}{l}\text { Merencanakan dan } \\
\text { mewujudkan harapan-harapan }\end{array}$ & 21,22 & 23,24 & 4 \\
\hline \multirow[t]{3}{*}{4} & Percaya diri & $\begin{array}{l}\text { Percaya pada kemampuan } \\
\text { sendiri }\end{array}$ & 25,26 & 27,28 & 4 \\
\hline & & $\begin{array}{l}\text { Berani mengambil resiko dan } \\
\text { menerima konsekuensinya }\end{array}$ & 29,30 & 31,32 & 4 \\
\hline & & Jumlah Butir & 16 & 16 & 32 \\
\hline
\end{tabular}

\section{Pembahasan}

Dalam kegiatan belajar akan dihasilkan 3 (tiga) aspek, yaitu, pengetahuan (kognitif), sikap (afektif), dan keterampilan (psikomotor). Aspek sikap atau afektif merupakan hal yang berkaitan dengan psikologi. Sehingga dalam penilaian dan pengukurannya diperlukan suatu instrumen non tes. Instrumen non tes digunakan dalam pengukuran aspek tersebut sehingga diperoleh data dalam bentuk angka atau data kuantitatif. Menurut Zainul (2001: 5) bahwa pengukuran merupakan proses pemberian angka atau usaha deskripsi numerik sejauh mana siswa telah mencapai suatu tingkatan. Pengukuran berhubungan dengan penentuan nilai kuantitatif. Sehingga pengukuran terkait dengan penentuan data kuantitatif.

Dalam kegiatan pengukuran diperlukan suatu instrumen atau alat ukur. Instrumen yang digunakan harus baku atau valid. Aiken (Harsiati, 2010: 54) menyatakan klasifikasi jenis tes secara dikotomi, yaitu tes baku dan tes non baku. Dalam pengembangan instrumen non tes harus dipenuhi beberapa langkah. Adapun langkah-langkah pengembangan alat ukur atribut non kognitif, yaitu, (1) Pengembangan spesifikasi alat ukur, (2) Penulisan pernyataan atau pertanyaan, (3) Penelaahan pernyataan atau pertanyaan, (4) Perakitan instrumen, (5) Uji coba, (6) Analisis hasil uji coba, (7) Seleksi dan perakitan instrumen, (8) Administrasi instrumen (bentuk akhir), dan (9) Penyusunan skala dan norma (Suryabrata, 2000: 178). 
Karakter kemandirian yang dikembangkan dalam upaya menunjang pengembangan sumber daya manusia Indonesia yang berkualitas. Kemandirian ini sangat penting terlebih bagi peserta didik dalam kegiatan pembelajaran. Hal ini disebabkan kemandirian merupakan salah satu faktor penunjang dalam keberhasilan belajar. Suhendri dan Mardalena (2013: 113) menyatakan bahwa kemandirian belajar merupakan salah satu faktor yang mendukung siswa dalam keberhasilan pembelajaran matematika, artinya kemandirian belajar memiliki pengaruh terhadap hasil belajar matematika.

Berdasarkan hal tersebut, maka perlu diupayakan pengembangan karakter kemandirian baik melalui pendidikan formal maupun non formal. Melalui pendidikan formal dilakukan dalam kegiatan belajar mengajar di kelas. Guru diupayakan dapat meningkatkan kemandirian siswa melalui kegiatan pembelajaran yang sesuai dan guru mengontrol setiap aktivitas belajar siswa. Suhendri (2011: 34) menyatakan bahwa kemandirian belajar siswa akan terwujud apabila siswa aktif mengontrol sendiri segala sesuatu yang dikerjakan, mengevaluasi dan selanjutnya merencanakan sesuatu yang lebih dalam pembelajaran yang dilalui dan siswa mau aktif dalam proses pembelajaran yang ada.

Selain melalui pendidikan formal, pengembangan kemandirian dapat melalui pendikan non formal yaitu melalui ekstrakurikuler pramuka, sedangkan menurut Sudrajad (2013) "Nilai-nilai kepramukaan adalah nilai-nilai positif yang diajarkan dan ditanamkan kepada para anggota pramuka. Nilai-nilai ini merupakan nilai moral yang menghiasi perilaku anggota pramuka. Dalam UU nomor 12 tahun 2010 tentang Gerakan Pramuka pasal 8 dinyatakan bahwa nilai kepramukaan mencakup: a) Keimanan dan ketaqwaan kepada Tuhan Yang Maha Esa, b) Kecintaan pada alam dan sesama manusia, c) Kecintaan pada tanah air dan bangsa, d) Kedisiplinan, keberanian, dan kesetiaan, e) Tolong menolong, f) Jernih dalam berpikir, berkata, dan berbuat, g) Hemat, cermat, dan bersahaja, dan h) Rajin dan terampil.

Nilai-nilai tersebut sangat penting dimiliki oleh semua warga negara Indonesia khususnya peserta didik dalam menghadapi perkembangan ilmu pengetahuan dan teknologi informasi. Sehingga peserta didik mampu memilah informasi dan pengetahuan yang diperoleh dari pemanfaatan teknologi informasi sehingga kepribadiannya tetap memiliki jiwa nasionalisme dan kepribadian yang baik.

\section{PENUTUP}

Berdasarkan hasil penelitian dan pembahasan, maka disimpulkan bahwa instrumen pengukuran kemandirian terdiri dari 4 dimensi dan 8 indikator serta 32 butir pernyataan. Instrumen pengukuran kemandirian dilengkapi dengan petunjuk pengisian dan petunjuk penggunaan. Hasil penelitian ini diharapkan menjadi acuan atau pedoman pengukuran variabel kemandirian bagi guru dan pendidik. Sehingga guru atau pendidik tidak melakukan pengukuran dalam penilaian karakter kemandirian peserta didik secara subjektif. Perlu dikembangkan penilaian dan pengukuran kemandirian yang lebih baik melalui kajian yang lebih mendalam.

\section{DAFTAR PUSTAKA}

Desmita. (2009). Psikologi Perkembangan Peserta Didik. Bandung: PT. Remaja Rosdakarya.

Djaali dan Muljono, P. (2008). Pengukuran dalam Bidang Pendidikan. Jakarta: Grasindo. 
Formatif: Jurnal Ilmiah Pendidikan MIPA

Vol. 8, No. 2, Agustus 2018, pp. 111-118

p-ISSN: 2088-351X

e-ISSN: $2502-5457$

DOI: http://dx.doi.org/10.30998/formatif.v8i2.2650

Harsiati, T. (2010). Pengembangan Alat Ukur Literasi Membaca Kritis-Kreatif dan Minat Baca Siswa. Disertasi PPs UNJ: Tidak dipublikasi.

Mardapi, D. (2011). Pengembangan instrumen pengukur hasil belajar nirbias dan terskala baku. Jurnal Penelitian dan Evaluasi Pendidikan, 15 (2), 326-341.

Patimah. (2011). Pendidikan Karakter melalui Program Ekstrakurikuler. http://skp.unair.ac.id/repository/Guru-Indonesia/PENDIDIKAN KARAKTER PATIMAH_16759.pdf.html. Diakses 2-12-2013.

Sugiyono. (2007). Metode Penelitian Pendidikan. Bandung: Alfabeta.

Suhendri, H. (2011). Pengaruh kecerdasan matematis-logis dan kemandirian belajar terhadap hasil belajar matematika. Formatif: Jurnal Ilmiah Pendidikan MIPA, 1 (1): 29-39.

Suhendri, H. dan Mardalena, T. (2013). Pengaruh metode pembelajaran problem solving terhadap hasil belajar matematika ditinjau dari kemandirian belajar. Formatif: Jurnal Ilmiah Pendidikan MIPA, 3(2): 105-114.

Suryabrata, S. (2000). Pengembangan Alat Ukur Psikologi. Yogyakarta: Penerbit Andi. Zainul, A. (2001). Penilaian Hasil Belajar. Jakarta: PAU-PPAI Universitas Terbuka. 